\title{
Fragility Hip Fracture and Sarcopenia: Which One Comes First?"
}

\author{
Héctor J Aguado ${ }^{1}$, Carmen Cervera ${ }^{1}$, Clarisa Simón ${ }^{1}$, Blanca Ariño ${ }^{2}$, Silvia Santiago ${ }^{2}$, Ricardo León ${ }^{2}$, Gonzalo \\ Martinez Municio $^{2}$ and Miguel A Martín Ferrero ${ }^{3 *}$
}

${ }^{1}$ Staff Doctor of Department of Orthopaedics (Geriatric Unity), Spain

${ }^{2}$ Training Doctor in Orthopaedics, Spain

${ }^{3}$ Professor and Head of Department of Orthopaedics, Spain

*Corresponding author: Miguel Angel Martin Ferrero, Hand Unit, Faculty of Medicine, University of Valladolid, Facultad de Medicina, Avenida Ramón y Cajal 5, 47005 Valladolid, Spain

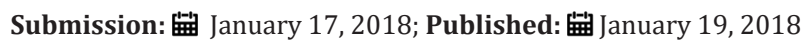

\section{Opinion}

Fragility fractures are usually related to other successive osteoporotic fractures [1-3]. Patients presenting a hip fracture, may suffer another sudden fall with the result of a contralateral hip fracture, a distal radius fracture, a proximal humeral fracture, a vertebral fracture or a periprosthetic fracture. Despite all the efforts for increasing bone mineral density (medical treatment, nutritional advice and moderate exercise), elderly patients keep falling down and presenting bone fractures. On the other side, aging has a direct impact on the skeletal muscle system: it is not only skeletal muscle mass loss, but also loss of muscle power and reaction speed; the so call sarcopenia. Little interest has been taken on this loss of muscle function, which might be related to the increase in the number of falls. And falls are a direct risk factor for bone fractures [4].

For the last two decades, osteoporosis has been considered epidemic and the main risk factor for fragility fractures. Thus, all the medical community and health organizations have been fighting to increase bone mineral density in frail patients, believing that fractures would decrease [5]. And indeed, there is a decrease in the incidence of fragility fractures in patients with any treatment adjusting bone's calcium metabolism, but not as much as desired. Why this decrease in secondary fragility fractures is not as much as expected? The reason is that there are many other risk factors for fragility fractures: mainly visual and sensory loss, altered balance, home hazard confusion, nutritional deficit, sleep disturbance and weakening of the skeletal muscle system. All these factors have one thing in common: they all directly influence in the risk of falls, which might end in a fragility fracture. Can we improve or palliate these risk factors? Certainly yes, but at a certain point: cataract surgery or adjusted glasses improve vision, a cane will help for the balance, home hazard reduction strategies, central nervous system medication might help diminishing confusion and sleep disturbance, and a balanced diet will improve the nutritional status $[6,7]$; but what do we do to strengthen the skeletal muscle system?
Sarcopenia may improve with counter resistance exercises, i.e. exercising in the water "aquagym", standing up from the seated position plus balance exercises or simply walking [5]. These exercises will improve skeletal muscle mass, muscle strength, and speed reaction. This improved scenario will give the patient enough resources to avoid a fall and recover the balance when tumbling, preventing from new fractures. Knowing these facts, fracture prevention programs should also focus on sarcopenia as it represents a major etiologic factor for fragility fractures.

Contrarily, an elderly patient who suffers a hip fracture, in the best scenario, is expected to be in bed or with reduced mobility for at least one week from the moment of the fracture. This lack of mobility means loss of skeletal muscle mass. The loss of skeletal muscle mass will put the patient under sarcopenia: increasing the risk of falls and the incidence of new fragility fractures [8]. But regarding this elderly patient presenting a hip fracture: how well did his skeletal muscle system work before the fracture? In a big number of cases, sarcopenia will be present [9] and it might be one of the etiologic factors of a hip fracture. In proximal femur fractures, elderly patients with sarcopenia are more likely to have prolonged hospitalization following surgery [10], closing a terrible vicious cycle.

Diagnosis of sarcopenia nowadays is still laborious: impedanciometry to assess skeletal muscle mass volume, a hand dynamometer to check muscle power, and the stand up and go test for muscle speed. It is not possible to assess the last parameter once the patient is in bed after the fracture. A new assessment tool should be developed to ease sarcopenia diagnosis.

Then, which comes first: the fragility hip fracture or sarcopenia? And the answer is: both of them are intimately tied. Sarcopenia might be present before a fragility hip fracture and a fragility hip fracture easies sarcopenia development. For this reason, a big 
effort should be made on sarcopenia prevention before and after a hip fracture. Exercise programs preventing sarcopenia before and after a proximal femur fracture should be mandatory according to the patient physical condition: group exercising before a fragility fracture and early weight bearing after a hip fracture surgery; including quick hospital discharge if possible as returning back home makes the patient walk and exercise the skeletal muscle system. Family doctors should also be aware of this problem as they can inform how to prevent sarcopenia in frail patients at risk of fragility hip fracture: prescribing specific exercises to gain speed reaction and muscle strength, and adapting the patient's diet to keep or gain skeletal muscle mass [11].

\section{References}

1. Pisani P, Renna MD, Conversano F, Ernesto Casciaro, Marco Di Paola, et al. (2016) Major osteoporotic fragility fractures: Risk factor updates and societal impact. World Journal of Orthopedics 7(3): 171-181.

2. Klotzbuecher CM, Ross PD, Landsman PB, Abbott TA, Berger M (2000) Patients with prior fractures have an increased risk of future fractures: a summary of the literature and statistical synthesis. J Bone Miner Res 15(4): 721-739.

3. Elliot Gibson V, Bogoch ER, Jama SA, Beaton DE (2004) Practice patterns in the diagnosis and treatment of osteoporosis after a fragility fracture: a systematic review. Osteoporosis International 15(10): 767-778.
4. Berry SD, Miller R (2008) Falls: Epidemiology, Pathophysiology, and Relationship to Fracture. Curr Osteoporos Rep 6(4): 149-154.

5. Montero Fernández N, Serra Rexach JA (2013) Role of exercise on sarcopenia in the elderly. Eur J Phys Rehabil Med 49(1): 131-143.

6. Campbell J Borrie MJ, Spears GF (1989) Risk Factors for Falls in a Community-Based Prospective Study of People 70 Years and Older. Journal of Gerontology 44(5): M112-M117.

7. Lord SR, Menz HB, Sherrington C (2006) Home environment risk factors for falls in older people and the efficacy of home modifications. Age Ageing 35(suppl 2): ii55-ii59.

8. Moreland JD, Richardson JA, Goldsmith CH, Clase CM (2004) Muscle weakness and falls in older adults: a systematic review and metaanalysis. J Am Geriatr Soc 52(7): 1121-1129.

9. González Montalvo JI, Alarcón T, Gotor P, Queipo R, Velasco R, et al. (2016) Prevalence of sarcopenia in acute hip fracture patients and its influence on short-term clinical outcome. Geriatr Gerontol Int 16(9): 1021-1027.

10. Chang CD, Wu JS, Mhuircheartaigh JN, Hochman MG, Rodriguez EK, et al. (2017) Effect of sarcopenia on clinical and surgical outcome in elderly patients with proximal femur fractures. Skeletal Radiol. doi: 10.1007/ s00256-017-2848-6.

11. Rubenstein LZ, Josephson KR, Trueblood PR, Steven Loy Judith O Harker, Fern M Pietruszka, et al. (2000) Effects of a group exercise program on strength, mobility, and falls among fall-prone elderly men. J Gerontol A BiolSci Med Sci 55A(6): M317-M321. 